\title{
REDESAIN SPEED CONTROL SUBMERGED SCRAPER CONVEYOR (SSC) BOTTOM ASH MENGGUNAKAN AC DRIVE
}

\author{
Faizal Riza ${ }^{l)}$, Ilmi Rizki Imaduddin ${ }^{2)}$ \\ Program Studi Teknik Elektro Fakultas Teknik Universitas Nurul Jadid \\ Karanganyar Paiton Probolinggo \\ Email :faizpjb07@gmail.com ${ }^{1)}$,Ilmirizki@gmail.com ${ }^{21}$
}

\begin{abstract}
ABSTRAK
Sistem kontrol penggerak Submerged Scrapper Conveyor (SSC) mempunyai peran yang sangat vital dalam proses kerja transportasi material limbah abu berat (bottom-ash) yang merupakan sisa hasil pembakaran batubara di boiler. Sistem kontrol penggerak SSC bekerja secara kontinyu 24 jam untuk menjaga agar material bottom ash tidak menumpuk di boiler hopper. Sistem ini harus selalu dijaga kehandalannya, karena apabila bermasalah maka akan berdampak langsung pada keberlangsungan operasi boiler di pembangkit yaitu menyebabkan derating.

Sistem kontrol penggerak eksisting pada SSC menggunakan speed variator. Speed variator bekerja secara mekanis untuk mengatur kecepatan dari SSC yaitu dengan sistem hidrolik transmisi. Kecepatan perlu diatur untuk mengendalikan laju material bottom ash akibat variasi beban pembangkit. Apabila beban tinggi, maka material bottom ash akan lebih banyak dibanding pada beban rendah. Sistem penggerak SSC di PLTU Paiton Unit 1 dan 2 dengan speed variator dewasa ini banyak mengalami permasalahan. Mulai dari overheating, kerusakan inner part, hingga spare part yang sudah tidak tersedia (obsolete), selain itu penurunan nilai kalori batubara yang dipakai pada boiler juga menambah beban pada SSC dikarenakan limbah bottom ash yang semakin banyak.

Untuk memaksimalkan kehandalan SSC di PLTU Paiton, maka dilakukan redesain speed control SSC. Redesain ini dilakukan dengan mengganti sistem kontrol penggerak SSC yang lama, yaitu speed variator dengan VFD (variable frequency drive) atau motor drive AC (Alternating Current). Redesain tersebut terdiri dari beberapa tahap, antara lain: (i) melakukan penggantian peralatan pada sistem kontrol penggerak SSC antara lain motor SSC serta mengganti speed variator dengan VFD, (ii) memodifikasi wiring dan logic pada PLC sistem untuk mengontrol kecepatan $S S C$, (iii) melakukan modifikasi panel kontrol sehingga operasi SSC dapat dimonitor di CCR Fly Ash HMI Human Machine Interface dan local control station baik secara auto atau lokal.
\end{abstract}

Kata kunci: speed variator, variable frequency drive (motor drive AC), sistem kontrol penggerak SSC 
JEECOM, Vol. 1, No. 1, Oktober 2019

\section{PENDAHULUAN}

\subsection{Latar Belakang Masalah}

PLTU Paiton Unit 1 \& 2 merupakan sebuah pembangkit listrik berbahan bakar batubara yang berlokasi di desa Bhinor, kecamatan Paiton, kabupaten Probolinggo, yang menyuplai energi listrik ke PLN sebesar 2 x 400 MW, dan berperan penting dalam proses supply energi listrik di jaringan transmisi Jawa-Bali.

Dalam proses operasi PLTU, bahan bakar berupa batubara dicampur dengan udara dan dibakar di dalam boiler untuk menghasilkan energi panas. Energi panas ini digunakan untuk mengubah air menjadi uap air dan digunakan untuk memutar turbin. Hasil dari putaran turbin inilah yang selanjutnya memutar generator yang di-couple dengan generator, sehingga dihasilkan energi listrik yang dialirkan ke sistem jaringan transmisi Jawa-Bali.

Pada unit PLTU terdapat sebuah equipment dinamakan SSC (Submerged Scraper Conveyor). SSC digunakan untuk menampung material hasil pembakaran berupa deposit atau jelaga dari dalam boiler. Material hasil pembakaran ini dinamakan dengan bottom ash. Bottom ash harus selalu di buang agar tidak menumpuk dan mengganggu operasi dan kinerja dari boiler. SSC mengirim bottom ash menuju bottom ash conveyor yang selanjutnya dimasukkan dan di tampung di bottom ash silo. Dari bottom ash silo, material bottom ash secara periodik akan di unload serta dibuang di disposal area menggunakan dump truck. SSC merupakan equipment yang penting karena SSC harus selalu beroperasi untuk membuang material bottom ash. Apabila SSC berhenti beroperasi pada beban penuh lebih dari 4 jam, maka unit harus turun beban (derating) sebesar 25\%. Hal ini bertujuan untuk mengurangii konsumsi bahan bakar agar material hasil pembakaran juga tidak terlalu banyak. Dengan diturunkannya beban ini, maka unit akan mengalami kerugian tiap waktunya.
Pada kondisi eksisting, SSC digerakkan oleh sebuah motor dengan daya $37 \mathrm{~kW}$. Motor ini ter-couple dengan sebuah alat dinamakan speed variator. Speed variator adalah sebuah alat yang digunakan untuk mengatur putaran motor dengan menggunakan prinsip transmisii hidrostatik dengan media oli. Untuk mengatur kecepatan motor, pada speed variator terpasang sebuah motor servo yang digerakkan oleh input sinyal 4-20 mA dari MCC. Motor servo ini menggerakkan swash plate yang kemudian merubah posisi dari piston pump yang menjadikan tekanan oli berubah sehingga mempengaruhi putaran dari motor. Kecepatan putar dari SSC perlu diatur untuk menyesuaikan dengan kondisi beban unit. Ketika unit pada kondisi beban penuh, maka SSC akan dinaikkan kecepatannya dikarenakan konsumsi batu bara tinggi, sehingga hasil pembakaran (bottom ash) akan lebih banyak. Sebaliknya, ketika beban rendah SSC akan diturunkan kecepatannya dari sebelumnya beban penuh, karena konsumsi batu bara lebih sedikit, sehingga hasil pembakaran (bottom ash) akan juga akan jauh lebih sedikit. Kondisi material hasil pembakaran harus selalu dijaga agar efisiensi dan keberlangsungan operasi boiler ikut terjaga.

Kondisi aktual saat ini, speed variator sering mengalami masalah dan banyak ditemukan ketidaknormalan ketika beroperasi. Permasalahan tersebut antara lain adalah:

a. Speed variator sering mengalami overheat pada olinya. Bahkan ketika telah dilakukan penggantian oli, temperatur pada speed variator masih tinggi. Salah satunya adalah kejadian pada tanggal 24 Maret 2014, ketika setelah dilakukan penggantian oli, dilakukan pengukuran temperatur, dan hasilnya temperatur mencapai $103^{\circ}$ Celcius. Hal tersebut dikhawatirkan akan merusak inner part dari speed variator dan kemacetan pada speed variator.

b. Ketersediaan part dari speed variator juga terbatas. Hal ini dikarenakan speed 
variator sudah tidak diproduksi lagi atau sudah obsolete sehingga proses maintenance pun ikut terkendala serta juga akan memakan cost yang tinggi karena dibutuhkan biaya tambahan untuk modifikasi part.

c. Dari kinerjanya yang kurang optimal, speed variator ini pada akhirnya membutuhkan konsumsi daya yang besar. Dengan operasi SSC yang terus menerus atau kontinyu, maka dapat dipastikan cost yang dibutuhkan juga tinggi dan penggunaan daya listrik yang besar.

\subsection{Rumusan Masalah}

Dari latar belakang masalah yang ada di atas, maka rumusan masalah yang dapat diambil adalah sebagai berikut:

a. Pengaruh kerusakan Submerged Scraper Conveyor (SSC) terhadap produksi listrik PJB Unit Pembangkitan Paiton 1 dan 2 ?

b. Apa pengaruh overheat pada speed variator terhadap kinerja Submerged Scraper Conveyor (SSC) ?

c. Langkah penyelesaian yang harus dilakukan untuk menekan biaya gangguan speed variator SSC yang terus berulang ?

d. Dampak Besarnya resiko kerja saat proses recovery gangguan SSC ?

\subsection{Tujuan Penelitian}

Tujuan dari penelitian ini adalah :

a. Mengkaji penyebab kerusakan speed variator pada saat SSC beroperasi.

b. Melakukan pemilihan alternatif solusi yang paling efektif untuk mengatasi permasalahan pada sistem penggerak (speed control) SSC.

c. Mendesain sistem penggerak (speed control) SSC yang handal, memudahkan operator dalam melakukan pengoperasian, serta memudahkan dalam maintenance.

d. Mengimplementasikan alternatif solusi pada sistem penggerak (speed control) SSC yang dipilih untuk memastikan kehandalan peralatan pembangkit.

\subsection{Manfaat Penelitian}

Faizal Riza : Redesain Speed Control Submerged ...
Manfaat yang diperoleh dari penelitian ini adalah sebagai berikut :

a. Meningkatkan kehandalan produksi listrik PJB Unit Pembangkitan Paiton

b. Mencegah derating produksi listrik PJB Unit Pembangkitan Paiton 1 dan 2 akibat gangguan pada sistem penggerak SSC.

c. Mengurangi permasalahan atau gangguan pada sistem penggerak SSC.

d. Mengurangi biaya recovery saat terjadi gangguan sistem penggerak SSC.

e. Meningkatkan kehandalan sistem penggerak SSC.

f. Mencegah potensi kecelakaan kerja saat proses recovery gangguan sistem penggerak SSC.

g. Mempermudah dalam pengoperasian dan pemeliharaan sistem penggerak SSC.

\section{KAJIAN PUSTAKA}

\subsection{Penelitian Terdahulu}

Penelitian terdahulu yang dilakukan meliputi penggunaan motor drive untuk pengaturan kecepatan lainnya, yaitu diantaranya Penerapan variable frequency drive pada motor fuel screw feeder untuk bahan bakar pada sistem boiler, Volume 2, No. 1, Januari 2014, Ishak Effendi. Pada pembahasan ini (VFD) Variable Frequency Drive atau motor drive AC (Alternating Current) dimanfaatkan pada penggerak fuel screw feeder. VFD ini digunakan untuk mengatur putaran dari motor fuel screw feeder, putaran motor yang di atur ini berfungsi mengatur flowrate dari batubara yang akan masuk ke boiler.

Penelitan selanjutnya adalah Pengujian unjuk kerja variable speed drive VF-S9 dengan beban 3 fasa 1 horse power, artikel ilmiah, Deni Nurul Huda. Pada penelitian ini motor drive $A C$ yang bertype $V F-S 9$ ini hanya di uji performance nya pada motor induksi 3 fasa. Hasil penelitan ini menjelaskan hanya cara kerja dan hasil pengukuran dari motor drive $A C$ yang dihubungkan pada motor 3 fasa 1 horse power. 
Penelitan yang lain dari penggunaan variable frequency drive adalah Implementasi sistem kendali variable speed drive pada inverter 3 fasa menggunakan mikrokontroller AT89S52, Volume 9, No. 1, April 2018, Emmanuel Agung Nugroho. Pada penelitian ini membahas tentang bagaimana cara membuat variable frequency drive dengan menggunakan microcontroller yang dihubungkan dengan motor induksi 3 fasa. Pengaturan frequency nya di program pada microcontroller AT89S52, dimana frequency dihasilkan dari IC LM 331.

Dari penelitian terdahulu diatas, penulis mengembangkan pemanfaatan Variable Frequency Drive (VFD) atau motor drive AC untuk system control speed Submerged Scrapper Conveyor (SSC) pada bottom ash PLTU Paiton Unit 1 dan 2.

\subsection{Dasar Teori}

\subsubsection{Bottom Ash System}

Bottom Ash System adalah sistem aliran material limbah hasil pembakaran batubara di boiler yang dimulai dari boiler hopper sampai ke bottom ash silo. Aliran limbah batubara hasil pembakaran di boiler keluar melalui boiler hopper, turun menuju ke Submerged Scraper Conveyor (SSC) dan dialirkan ke bottom ash chute, kemudian dikirim oleh bottom ash conveyor ke bottom ash silo. Di dalam bottom ash chute ini terdapat crusher grinder yang berfungsi untuk menghancurkan material limbah batubara yang berukuran besar menjadi lebih kecil agar mudah diangkut dan tidak merusak conveyor. Material limbah yang sudah halus ini selanjutnya dialirkan dan ditampung ke bottom ash silo untuk selanjutnya dibuang ke disposal area. Diagram dari bottom ash system ditunjukkan pada gambar 2.1 dibawah ini.

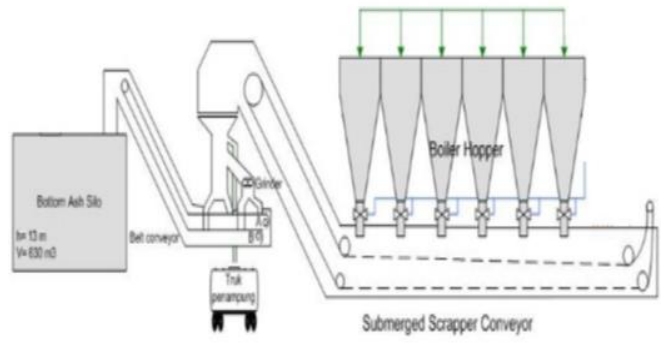

Gambar 2.1 Bottom ash system

(Sumber : Manual Book O\&M Ash Handling System PLTU Paiton)

\subsubsection{Submerged Scrapper Conveyor (SSC)} Merupakan equipment yang berfungsi untuk membawa material bottom ash hasil pembakaran batu bara pada furnace di dalam boiler menuju ke bottom ash silo melalui bottom ash conveyor. Hasil pembakaran yang di bawa oleh SSC merupakan material batu bara yang tidak terbakar serta residu hasil proses pembersihan furnace (soot blowing) yang jatuh ke dalam SSC. SSC berupa bak besar berisi air yang terletak tepat di bawah boiler dimana terdapat scraper conveyor di dalamnya. Air tersebut merendam bagian mulut bawah boiler serta conveyor yang ada di dalam SSC. Fungsi dari air tersebut adalah sebagai seal dari lubang mulut boiler serta sebagai pendingin material hasil pembakaran yang jatuh secara gravitasi. Material hasil pembakaran yang jatuh dari dalam boiler sebelum di bawa oleh scraper conveyor, terlebih dahulu ditampung oleh hopper SSC sebanyak 6 buah. Hopper tersebut mengkondisikan material yang jatuh agar tepat berada di dalam SSC. SSC memiliki sistem penggerak (driving mechanism) ekisting yang terdiri atas motor, speed variator, gear reducer, sprocket serta scraper conveyor itu sendiri. Sistem penggerak tersebut beroperasi secara terus menerus untuk menjaga agar bottom ash selalu 
terdistribusi dengan baik, sehingga tidak ada penumpukan material bottom ash. Pada gambar 2.2 dibawah ini merupakan bak submerged scrapper conveyor, sedangkan pada gambar 2.3 merupakan sistem penggerak existing SSC yang menggunakan speed variator sebagai pengaturan kecepatan.

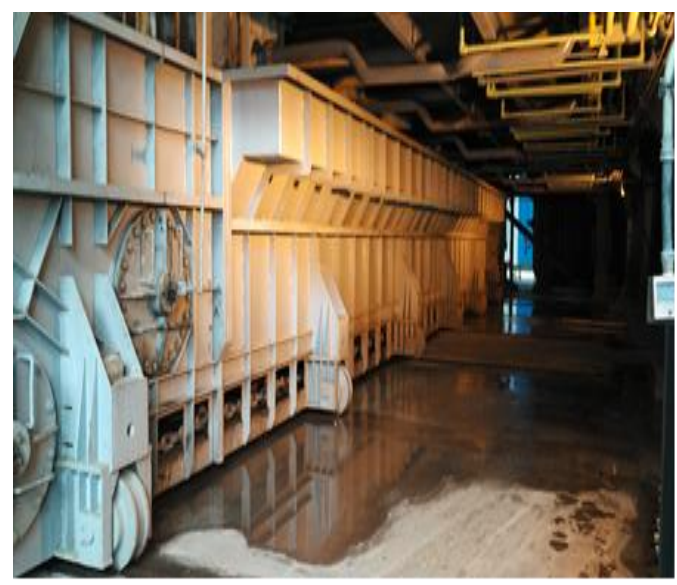

Gambar 2.2 Foto Submerged Scrapper Conveyor

( Sumber : Dokumen foto PLTU Unit $1 \& 2$ )

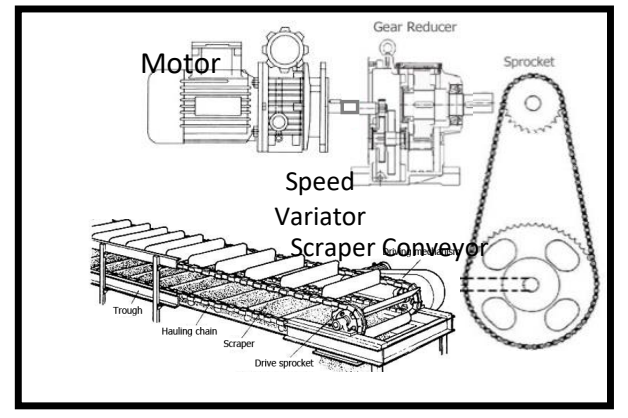

Gambar

Sistem

Speed

Variator

Submerged Scrapper Conveyor

( Sumber : Google Images)

\subsubsection{Speed Variator}

Speed variator adalah sebuah peralatan mekanis untuk merubah kecepatan putar motor maupun arah putaran motor SSC (Submerged Scrapper Conveyor). Speed variator yang digunakan mengaplikasikan transmisi hidrostatik untuk variasi kecepatan motor. Transmisi hidrostatik bekerja dengan fluida oli. Oli bergerak berdasarkan gerakan dari swash plate. Ketika motor diputar, maka piston pump akan ikut berputar. Apabila swash plate ada di posisi tengah, maka tidak ada oli yang dipompa, dengan kata lain oli akan diam, tekanan ekual, sehingga tidak menghasilkan putaran. Apabila swash plate diarahkan ke kanan, maka piston pump akan memompa oli. Hal ini terjadi akibat pump motion dari piston pump yang berputar menghasilkan perbedaan tekanan, sehingga oli akan mengalir. Jika swash plate semakin diarahkan ke kanan, maka piston pump akan memompa lebih kuat, tekanan semakin besar, sehingga menghasilkan torsi yang lebih besar serta putaran yang semakin kencang. Hal tersebut bekerja pada arah sebaliknya.

Pada speed variator, terdapat servo motor yang mendapatkan sinyal dari control station untuk menggerakkan swash plate. Swash plate tersebut terkopel pada hydraulic piston pump. Swash plate inilah yang menentukan berapa bukaan dari hydraulic piston pump untuk mengatur kecepatan putar serta posisinya pada forward atau reverse. Pada speed variator terdapat pula sebuah feedback, yaitu speed indicator untuk memastikan apakah motor sudah beroperasi pada RPM yang diinginkan. Pada instalasinya, speed variator terkopel satu set langsung dengan motor. Gambar 2.5 dibawah ini merupakan Speed Variator existing SSC. 
JEECOM, Vol. 1, No. 1, Oktober 2019

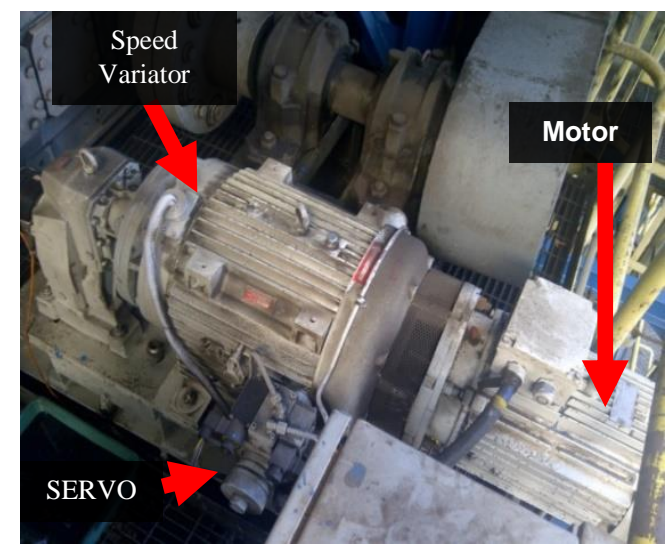

Gambar 2.5 Speed variator existing

( Sumber : Dokumen foto PLTU Unit $1 \& 2$ )

2.2.4 Motor Submerged Scrapper Conveyor (SSC)

Merupakan penggerak utama SSC. Motor yang digunakan adalah jenis motor induksi 3 phasa dengan tegangan kerja 400 Volt, frekwensi 50 $\mathrm{Hz}$, dan daya $37 \mathrm{~kW}$. Motor ini memiliki range RPM 0 - 1470/min. Namun pada kondisi normal hanya dioperasikan pada kisaran RPM 300 /min. Motor ini memiliki 4 pole dan cos phi 0.87 dengan arus 66 A. Pada gambar 2.6 dibawah ini merupakan motor yang digunakan pada SSC PLTU Paiton unit 1 dan 2.

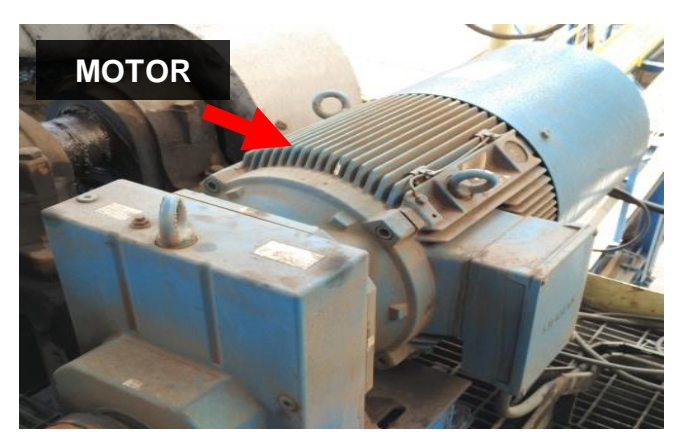

Gambar 2.6 Motor Submerged Scrapper Conveyor

( Sumber : Dokumen foto PLTU Unit 1 \& 2 )

Motor induksi SSC ini terdiri dari dua bagian yang sangat penting yaitu stator atau bagian yang diam dan Rotor atau bagian berputar. Pada motor $A C$, kumparan rotor tidak menerima energi listrik secara langsung, tetapi secara induksi seperti yang terjadi pada energi kumparan transformator. Oleh karena itu motor $A C$ dikenal dengan motor induksi. Motor induksi ini mempunyai keuntungan sebagai berikut:

a) Bentuknya yang sederhana dan memiliki konstruksi yang kuat dan hampir tidak pernah mengalami kerusakan yang berarti.

b) Harga relatif murah dan dapat diandalkan.

c) Efisiensi tinggi pada keadaan berputar normal, tidak memerlukan sikat sehingga rugi - rugi daya yang diakibatkannya dari gesekan dapat dikurangi.

d) Perawatan waktu mulai beroperasi tidak memerlukan starting tambahan khusus dan tidak harus sinkron.

Namun disamping memiliki kelebihan, terdapat pula faktor - faktor kerugian yang tidak menguntungkan dari motor induksi yaitu sebagai berikut

a) Pengaturan kecepatan dari motor induksi sangat mempengaruhi efesiensinya.

b) Kecepatan motor induksi akan menurun seiring dengan bertambahnya beban, tidak seperti motor DC atau motor shunt.

c) Kopel awal mutunya rendah dibandingkan dengan motor $D C$ shunt.

Pada motor induksi dapat berputar atau mengalirkan arus pasti memerlukan tegangan induksi, agar tegangan terinduksi diperlukan adanya perbedaan relatif antara kecepatan 
JEECOM, Vol. 1, No. 1, Oktober 2019

medan putar stator (ns) dengan kecepatan berputar rotor $(n r)$. Perbedaan kecepatan pada motor induksi ini disebut juga Slip (S), Slip ini dapat dinyatakan dengan :

Slip $(S)=\frac{\mathrm{ns}-\mathrm{nr}}{\mathrm{ns}} \times 100 \%$

Dimana motor SSC memiliki kecepatan medan putar stator (ns) sebesar 1500 rpm dan kecepatan berputar rotor $(n r)$ sebesar $1470 \mathrm{rpm}$, maka motor SSC memiliki Slip motor sebesar :

$$
\text { Slip }(S)=\frac{1500-1470}{1500} \times 100 \%=2 \%
$$

\subsubsection{Gear Reducer}

Sebuah peralatan yang berfungsi untuk mereduksi putaran motor SSC (Submerged Scrapper Conveyor). Gear reducer SSC ini terdiri atas gear yang memiliki rasio tertentu. Perbandingan rasio gear di dalam gear reducer ini akan menghasilkan perbedaan putaran antara input gear box dan output gear reducer. Terdapat 2 buah gear reducer pada SSC, pertama adalah main gear reducer dan yang kedua adalah auxiliary gear reducer (aux gear reducer ini ada setelah dilakukan redesain dari speed variator menjadi Variable Frequency Drive). Rasio reduksi total dari main gear reducer SSC adalah 1350/8,43 = 160,095. Sedangkan rasio dari auxiliary gear reducer adalah 1 : 1,36. Auxiliary gear reducer dipasang untuk menyesuaikan spesifikasi motor yang baru dengan spesifikasi sistem eksisting. Pada gambar 2.7 dibawah ini merupakan gear reducer dan aux gear reducer yang digunakan pada $S S C$.

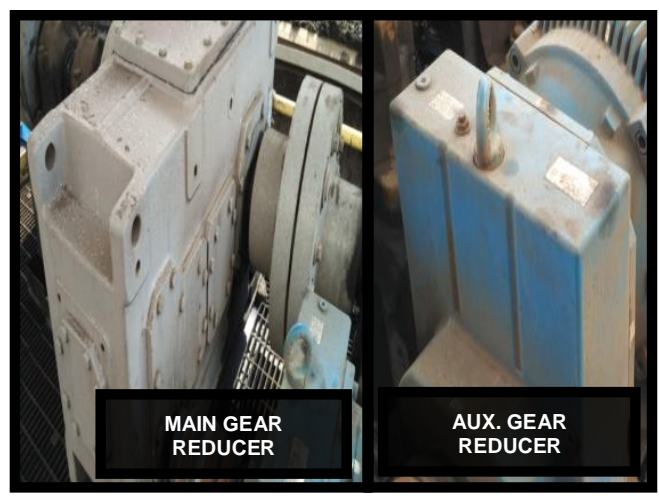

Gambar 2.7 Main dan aux gear reducer Submerged Scrapper Conveyor

( Sumber : Dokumen foto PLTU Unit $1 \& 2$ )

\subsubsection{Programmable Logic Control (PLC)}

Pusat dari pengaturan dan pengontrolan sistem Bottom Ash berupa Programmable Logic Controller atau biasa yang disingkat dengan $P L C$. $P L C$ secara hirarki sebagai sistem control yang berfungsi untuk mengendalikan suatu proses di dalam industri. PLC selayaknya seperti personal computer yang memiliki Central Processing Unit, Processor, dan Memory (RAM). PLC adalah pengembangan dari relay konvensional. PLC dapat disusun dari fungsi yang sederhana hingga komplek. Pada umumnya output dari PLC dihubungkan dengan relay atau komponen utama lain. Secara unum diagram $P L C$ dapat digambarkan pada gambar 2.8 dibawah ini.

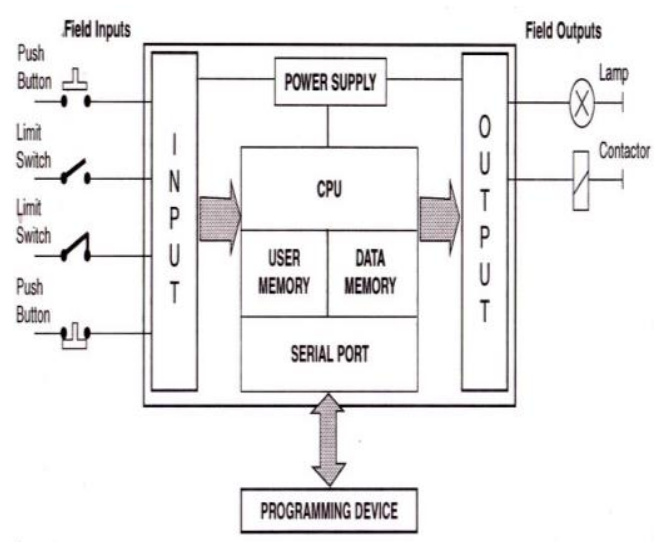


JEECOM, Vol. 1, No. 1, Oktober 2019

Gambar 2.8 Diagram umum PLC

( Sumber : Google Images)

Pada sistem PLC ash handling menggunakan PLC Modicon Quantum Schneider. Central Processing Unit (CPU) PLC ash handling ini bekerja secara redundant hot standby, dimana apabila salah satu CPU fault atau off maka otomatis $C P U$ yang satunya mengambil alih proses datanya. Pada sisi input dan outputnya terdiri dari 5 drop input output yang semua drop input outputnya dikomunikasikan menggunakan kabel fiber optic secara redundant ring yang bisa komunikasi dua arah. Apabila fiber optic putus, maka komunikasi data tetap normal. Untuk bisa terhubung dengan drop input output dan $C P U$, fiber optic ini dikonversi ke ethernet oleh manage switch. Gambar 2.9 dibawah ini adalah sistem arsitektur komunikasi pada PLC ash handling.

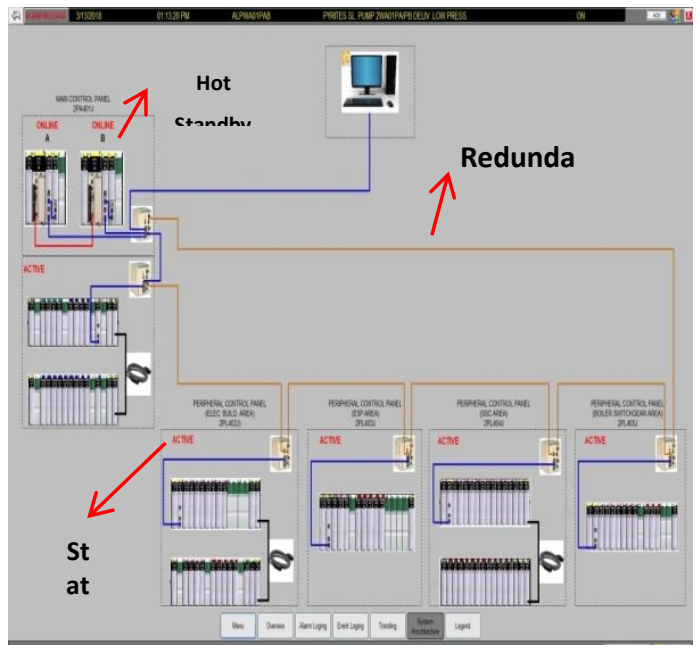

Gambar 2.9 Sistem arsitektur PLC Ash Handling

( Sumber : Human machine interface ash handling PLTU Paiton 1 \& 2)

\section{METODE PENELITIAN}

\subsection{RANCANGAN PENELITIAN}

Dalam melakukan rancangan penelitian ini, penulis mengajukan judul penelitian redesain speed control Submerged Scrapper Conveyor (SSC) dengan menggunakan motor drive di PLTU Paiton unit 1 dan 2. Pada penelitian ini penulis melakukan perubahan pada penggerak atau speed control Submerged Scrapper Conveyor (SSC) yang awalnya menggunakan speed variator dengan sistem hidrolik transmisi menjadi menggunakan penggerak atau speed control motor drive AC ( Alternating Current ). Pada penggerak speed variator sistem hidrolik ini, motor berputar konstan di putaran 1500 rpm dan untuk pengaturan kecepatannya dengan mengatur swash plate. Swash plate mengatur tekanan minyak sehingga dpat diatur kecepatnnya yang diatur oleh servo motor. Sedangkan pada desain baru menggunakan motor drive, pengaturan kecepatannya dengan merubah ubah kecepatan dari motor yang diatur oleh motor drive AC. Desain ulang dilakukan karena seringnya terjadi abnormal atau macet pada penggerak SSC. Gangguan ini menyebabkan potensi derating dan MWH (Mega Watt Hours) losses pada PLTU Paiton unit 1 dan 2. Selain seringnya gangguan macet pada penggerak SSC, spare part dari speed variator ini sudah obsolete sehingga apabila selama ini ada kerusakan hanya dilakukan repair yang potensi kerusakannya bisa berulang. Adapun diagram alir atau flowchart dari proses redesain penggerak speed control SSC ini dijelaskan pada gambar 3.1 dibawah ini. 
JEECOM, Vol. 1, No. 1, Oktober 2019

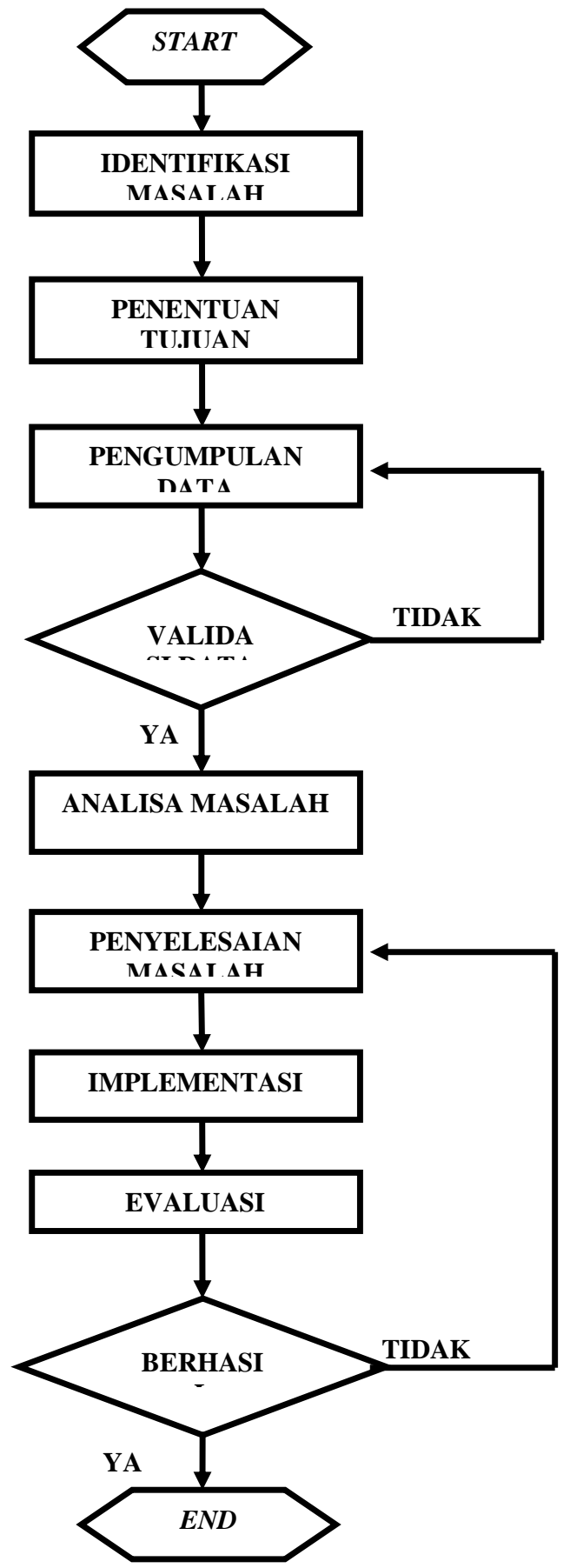

Gambar 3.1 Flowchart redesain speed control Submerged Scrapper Conveyor bottom ash

Pada gambar 3.1 dijelaskan bahwa terdapat beberapa tahap dan langkah dalam melakukan redesain speed control SSC dengan menggunakan motor drive $A C$ yang akan dijelaskan sebagai berikut :

1. Start

Frekuensi gangguan speed variator yang terjadi.

2. Identifikasi masalah

Setelah melakukan analisa dan breakdown, gangguan yang sering terjadi di Submerged Scrapper Conveyor adalah overheating pada speed variator yang menggunakan sistem hydroulic transmission.

3. Penentuan tujuan

Berusaha untuk menurunkan permasalahan gangguan abnormal atau macet pada penggerak Submerged Scrapper Conveyor (SSC) dan menurunkan jumlah work order gangguan Submerged Scrapper Conveyor (SSC) yang dapat berpotensi menimbulkan derating atau $M W H$ losses.

4. Pengumpulan data

Mengumpulkan data gangguan dilakukan mulai tahun 2010.

5. Validasi data

Data yang diperoleh dari identifikasi dan perbaikan sesuai work order pada SSC valid disebabkan oleh gangguan pada speed control speed variator SSC yang overheat.

6. Analisa masalah

Penyebab penggerak speed control SSC abnormal atau macet disebabkan seringnya overheat pada speed variator SSC, sistem transmisi hidrolik sebagai penggerak SSC kurang optimal seiring dengan banyaknya material bottom ash dan spare part yang dipakai untuk perbaikan speed variator hasil dari repair yang kurang bagus, repair ini dilakukan karena spare part sudah obsolete.

7. Penyelesaian masalah 
JEECOM, Vol. 1, No. 1, Oktober 2019

Melakukan desain ulang pada penggerak speed control SSC menggunakan motor drive $A C$ yang lebih handal dan effisien dalam konsumsi dayanya serta motor drive $A C$ ini memiliki berbagai macam fitur untuk proteksi.

8. Implementasi

Pembuatan Engineering Change Proposal ( ECP ) dikarenakan merubah desain eksisting. Setelah $E C P$ disetujui, redesain speed control Submerged Scrapper Conveyor (SSC) dilaksanakan pada saat overhoul di unit 2 terlebih dahulu pada tahun 2015 .

9. Evaluasi

Setelah dilakukan redesain speed control Submerged Scrapper Conveyor menggunakan motor drive $A C$ ini, gangguan dan permaslahan SSC macet menurun bahkan tidak pernah terjadi.

10. Berhasil

Redesain speed control SSC dengan motor drive AC ini berhasil menurunkan dan menghilangkan gangguan SSC yang macet atau abnormal pada sistem penggeraknya.

11. End

Selesai dan dapat diterapakan pada penggerak atau speed control Submerged Scrapper Conveyor yang lainnya yang masih menggunakan sistem hidrolik transmisi.

\subsection{Teknik Pengumpulan Data}

\section{Dokumentasi}

Dokumentasi adalah salah satu metode pengumpulan data kualitatif dengan melihat atau menganalisis dokumen-dokumen yang dibuat oleh subjek sendiri atau oleh orang lain tentang subjek. Adapun dalam sumber data dalam penelitian ini adalah :
1. Manual book thermokimik ash handling system

2. Manual book variable frequency drive

3. Data pengukuran speed variator

4. Data tarikan work order ellips

5. Laporan harian operator

6. Manual book Programable Logic Control (PLC) modicon quantum schneider

\section{Observasi}

Observasi merupakan kegiatan pemuatan penelitian terhadap suatu objek. Apabila dilihat pada proses pelaksanaan pengumpulan data, observasi dibedakan menjadi partisipan dan non-partisipan. Jenis observasi yang digunakan pada penelitian ini adalah observasi non-partisipan. Dalam melakukan observasi, peneliti memilih hal-hal yang diamati dan mencatat halhal yang berkaitan dengan penelitian. Adapun hal - hal yang perlu di observasi adalah seringnya muncul work order pada submerged scrapper conveyor dan overheat pada speed variator dan kuantitas limbah botom ash.

\section{Studi Literatur}

Studi literatur dengan cara melakukan kajian teori melalui internet (jurnal). Jurnal sebagai acuan dan mempelajari penelitian yang akan diterapkan di PLTU UP Paiton yakni mencegah dan mengurangi gangguan pada Submerged Scrapper Conveyor (SSC) dengan melakukan redesign sistem penggerak submerged scrapper conveyor menggunakan variable frequency drive atau motor drive $A C$, dengan mempertimbangkan jurnal jurnal serta informasi yang ada di internet, serta informasi dari pihak 
JEECOM, Vol. 1, No. 1, Oktober 2019

manufaktur untuk mendapatkan hasil yang baik.

\section{Desain Penelitian}

Desain penelitian merupakan hal terpenting dalam penulis melakukan penelitan. Desain penelitian yang dilakukan dalam redesain speed control Submerged Scrapper Conveyor (SSC) bottom ash menggunakan motor drive $A C$ (Alternating Current) agar bisa beroperasi dengan baik adalah :

\section{HASIL DAN PEMBAHASAN}

\subsection{Penyajian Data}

1. Penggerak Submerged Scrapper Conveyor (SSC) Sebelum Redesain

Sebelum dilakukan redesain, awalnya speed control penggerak SSC menggunakan speed variator dengan sistem hydroulic transmission. Untuk pengaturan kecepatannya dan arah putaran dikontrol oleh servo motor yang berfungsi mengatur pergerakan swash plate, swash plate tersebut yang mengatur tekanan minyak untuk pengaturan kecepatan dan arah putaran SCC. Servo motor ini dikendalikan oleh Programmable Logic Control (PLC) ash handling. Dalam sistem ini kecepatan motor konstan atau tetap yaitu $1500 \mathrm{rpm}$. Gambar 4.1 dibawah ini merupakan diagram speed control SSC sebelum dilakukannya redesign.

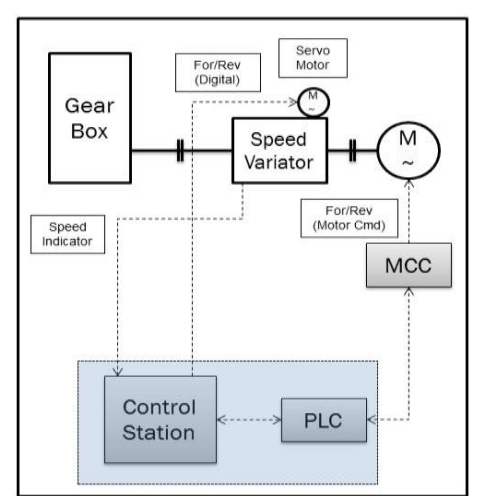

Gambar 4.1 Diagram speed control SSC yang lama

( Sumber : Faizal, 2015 )

Pada gambar 4.1 dijelaskan bahwa sinyal kontrol dari PLC digunakan untuk memberikan command pada motor melalui Motor Control Centre ( MCC ) breaker dan sinyal pengaturan ke servo motor. Input PLC menerima sinyal status running motor dari $M C C$ breaker untuk diolah di logic program PLC sebagai permit dan interlock, sedangkan servo motor menerima sinyal dari PLC untuk mengatur arah dan kecepatan dari speed variator yang digunakan untuk menggerakkan SSC. Untuk mengetahui kecepatan putaran dari speed variator, PLC menerima sinyal dari speed variator yang kemudian ditampilkan pada indikator speed. Kecepatan saat operasi normal di keluaran speed variator yang menuju ke gearbox adalah $1000 \mathrm{rpm}$, sedangkan kecepatan Submerged Scrapper Conveyor (SSC) adalah 1.2 meter per menit.

2. Permasalahan Abnormal Atau Macet Pada Speed Variator

Submerged Scrapper Conveyor (SSC) ini beroperasi secara terus menerus selama 24 jam penuh dalam setahun sehingga diperlukan kehandalan pada SSC ini, akan tetapi sistem speed variator yang lama ini 
selain sudah obsolete spare part materialnya juga sering mengalami overheat atau panas berlebih pada minyak hidroliknya. Overheat ini menyebabkan SSC menjadi abnormal atau macet. Hal ini dapat mengakibatkan transportasi limbah padat bottom ash pada boiler terganggu sehingga menimbulkan potensi derating daya listrik pada pembangkit listrik PLTU Paiton Unit 1 \& 2 apabila perbaikannya melebihi 4 jam. Dampak derating ini sangat merugikan pada perusahaan. Tabel 4.1 dibawah ini merupakan sebagian atau sample work order atau pekerjaan kerusakan pada SSC yang dibuat operator di kedua unit yaitu unit $1 \& 2$ yang disebabkan oleh overheat.

Tabel 4.1 Work order kerusakan speed variator

\begin{tabular}{|c|c|c|}
\hline $\begin{array}{c}\text { Number Work } \\
\text { Order }\end{array}$ & Work Order Description & Tahun \\
\hline 00049255 & SSC unit 1 alarm trip di panel CCR & 2010-02-02 \\
\hline 00050147 & Chain SSC\#1 kendor & 2010-03-04 \\
\hline 00052342 & SSC \#1 trip dan scrapper lepas 2 buah & 2010-05-03 \\
\hline 00058030 & Speed Variator \#1 Ada Kebocoran Oil & 2010-10-27 \\
\hline 00058252 & SSC \#1 Muncul Alarm Trip & 2010-11-02 \\
\hline 00059650 & SSC\#1 rantai kendor & 2010-12-13 \\
\hline 00061565 & SSC \#2 sering trip & 2011-02-02 \\
\hline 00062548 & $\begin{array}{l}\text { Submerged Scrapper Conveyor System \#2 } \\
\text { abnormal }\end{array}$ & 2011-03-03 \\
\hline 00062775 & Chain SSC\#2 kendor & 2011-03-09 \\
\hline 00063734 & SSC \#2 putaran lambat & 2011-04-07 \\
\hline 00060562 & Indikasi SSC Trip Unit-1 nyala terus & 2011-01-03 \\
\hline 00062276 & SSC \# 1 rantai kendor & 2011-02-22 \\
\hline 00070127 & SSC \#1 Macet Motor Gear Box Slip & 2011-10-08 \\
\hline 00070135 & SSC \#1 Guide Scrapper putus & 2011-10-10 \\
\hline 00072823 & Repair SpeedVariator eks SSC\#1 & $2011-12-23$ \\
\hline 00073769 & Penormalan SSC \#1 & 2012-01-18 \\
\hline 00074278 & SSC \#1 speed tidak bisa di adjust & 2012-01-31 \\
\hline 00075018 & SSC \#1 sering trip chain breakage & $2012-02-23$ \\
\hline 00075719 & SSC \#1 abnormal & 2012-03-09 \\
\hline 00076949 & SSC\#1 rantai kendor & 2012-04-19 \\
\hline 00085315 & Penggantian speed variator SSC \#1 & 2012-12-26 \\
\hline 00088059 & BasaltTile \& Speed Variator SSC\#1 abnormal & 2013-03-18 \\
\hline 00098119 & speed variator SSC\#1 oli bocor & 2013-12-23 \\
\hline 00118645 & Seal speed variator SSC \#1 bocor & 2015-03-03 \\
\hline 00120487 & Speed variator SSC \#1 oil rembes & 2015-04-02 \\
\hline
\end{tabular}

Dari data kerusakan pada tabel 4.1 dampak dari overheating sangat besar mempengaruhi kehandalan dari SSC, maka dari itu diperlukan perubahan design penggerak SSC.

\section{Penambahan Oil Cooler Pada Speed Variator}

Dari banyaknya gangguan permasalahan sistem penggerak Submerged Scrapper Conveyor (SSC) yang menggunakan speed variator hidrolik transmisi yang disebabkan dari overheating, maka sebagai langkah awal untuk mendinginkan overheat tersebut ditambahkanlah oil cooler untuk mendinginkan minyak hidrolik transmisinya. Dari hasil pengujian, langkah ini ternyata tidak efektif karena saat speed variator masih tidak berbeban, temperature speed variator cenderung tinggi dan apabila di operasikan tanpa beban lebih dari 10 jam speed variator mulai macet lagi. Gambar 4.2 dibawah ini adalah penanganan awal dengan penambahan oil cooler.

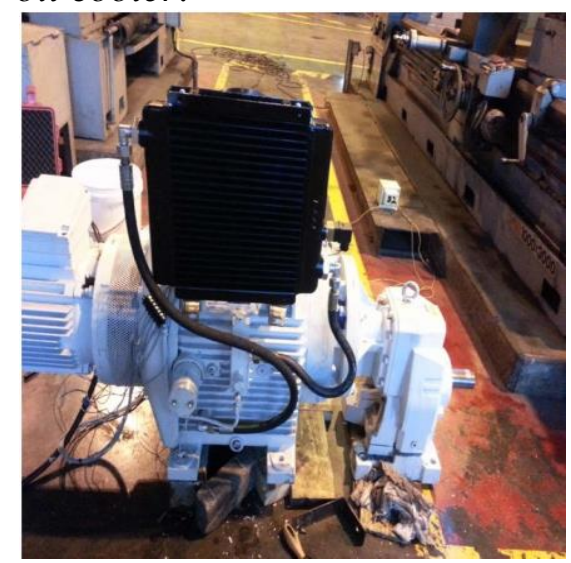

Gambar 4.2 Penambahan oil cooler pada speed variator

Dari hasil penambahan oil cooler pada speed variator, temperature pada speed variator cenderung ada peningkatan yang cukup signifikan, padahal pada saat pengujian dan pengamatan speed variator masih dalam posisi tidak ada beban SSC atau no 
load. Tabel 4.2 dibawah ini merupakan hasil pengukuran temperature pada speed variator yang sudah dilakukan penambahan oil cooler.

\subsection{Pembahasan}

\section{a. Desain Speed Control Submerged Scrapper Conveyor (SSC) Menggunakan Motor Drive AC}

Seringnya terjadi overheat pada speed variator, maka penulis melakukan perubahan desain dengan merubah penggerak speed control Submerged Scrapper Conveyor (SSC) pada PLTU Paiton unit 1 \& 2 menggunakan Variable Frequency Drive (VFD) atau motor drive $A C$ (Alternating Current). Gambar 4.14 dibawah ini merupakan diagram perubahan design Submerged Scrapper Conveyor (SSC) menggunakan Variable Frequency Drive (VFD) atau motor drive AC.

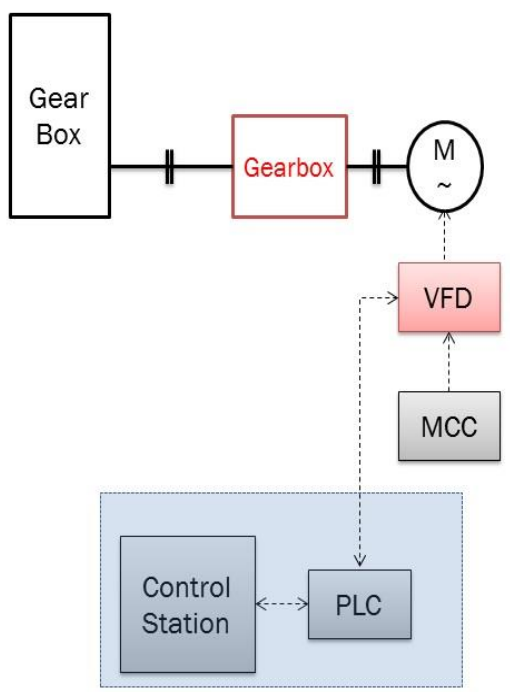

Gambar 4.3 Diagram speed control SSC menggunakan motor drive (VFD)

Untuk pengaturan kecepatannya, modul analog input VFD menerima signal 4 $m A$ sampai $20 \mathrm{~mA}$ dari modul analog output PLC modicon quantum Schneider dengan type ACO 020 00, signal ini diolah menggunakan program ledder diagram oleh CPU 67160. Minimum speed saat start awal adalah $75 \mathrm{rpm}$, saat operasi normal tanpa sootblower di boiler diatur pada kecepatan $250 \mathrm{rpm}$, sedangkan saat kegiatan sootblower di boiler diatur kecepatannya menjadi $300 \mathrm{rpm}$. Kenaikan rpm ini diatur oleh tombol increase dan decrease yang merupakan signal digital dari tombol. Signal digital ini masuk ke digital input DAI 54300 , begitu juga dengan status dari kondisi drive yang sedang running forward, running reverse dan status stop. Sinyal digital output dari VFD mengirimkan sinyal digital ke modul digital input PLC DAI 543 00. Pada saat speed minimum dan saat speed nominal tanpa sootblower maupun dengan sootblower dapat dihitung dengan rumus :

\section{Output Arus $\mathbf{m A}=\{[($ indikasi - zero $)$} $x$ span) $] /$ Range $\}+4$

Dimana pada kecepatan minimum speed $75 \mathrm{rpm}$ dapat dketahui nilai output analog $m A$ arusnya, yaitu :

Zero analog $=0 \mathrm{~mA}$, Span analog $=20$ $\mathrm{mA}-4 \mathrm{~mA}=16 \mathrm{~mA}$

Range $=1500 \mathrm{rpm}$

Output Arus $\mathrm{mA}=\{[(75-0) \times 16)] /$ $1500\}+4$

$$
\begin{aligned}
& =0.8+4 \\
& =4.8 \mathrm{~mA}
\end{aligned}
$$

Pada kecepatan nominal speed tanpa sootblower sebesar $250 \mathrm{rpm}$ dapat diketahui nilai output analog $\mathrm{mA}$ arusnya, yaitu :

Output Arus $\mathrm{mA}=\{[(250-0) \times 16)] /$ $1500\}+4$

$$
\begin{aligned}
& =2.67+4 \\
& =6.67 \mathrm{~mA}
\end{aligned}
$$

Pada kecepatan nominal speed dengan sootblower sebesar $300 \mathrm{rpm}$ dapat 
diketahui nilai output analog $m A$ arusnya, yaitu :

Output Arus mA $=\{[(300-0) \times 16)] /$ $1500\}+4$

$$
\begin{aligned}
& =3.2+4 \\
& =7.2 \mathrm{~mA}
\end{aligned}
$$

Sedangkan alur pemrosesan sinyal analog pada Programable Logic Control (PLC) ini dapat digambarkan dan dijelaskan pada gambar 4.15. Untuk alur proses sinyal digital input dijelaskan pada gambar 4.16.

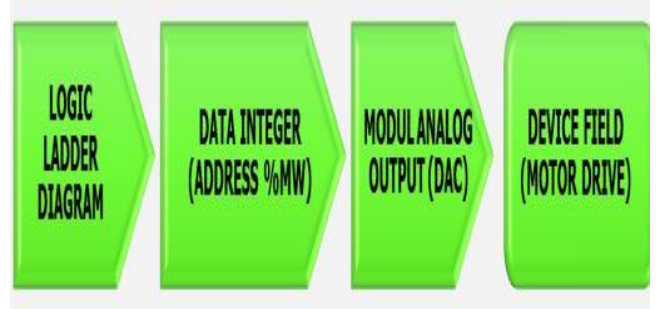

Gambar 4.4 Alur proses sinyal analog output

\section{PENUTUP}

\subsection{Kesimpulan}

Kesimpulan yang dapat diambil dari penyusunan redesain ini, adalah sebagai berikut:

1. Permasalahan pada speed variator disebabkan oleh nilai kalor batu bara yang semakin menurun dan overheat.

2. Untuk mengatasi permasalahan pada speed variator, maka dilakukan redesain speed control Submerged Scrapper Conveyor (SSC) dengan mengganti speed variator menjadi motor drive .

3. Hasil implementasi dari motor drive (Variable Frequency Drive) menunjukkan bahwa selain handal, juga efisien. Terbukti dangan jarang terjadi masalah pada motor drive , serta kemudahan dalam mengoperasikan dan maintenance.

4. Redesain ini memberikan manfaat diantaranya peningkatan kehandalan dan efisiensi, keselamatan kerja, kemudahan pengoperasian, energy saving, dan kemudahan pemeliharaan, serta ramah lingkungan.

\subsection{Saran}

Adapun saran yang dapat disampaikan terkait dengan redesain ini adalah sebagai berikut:

1. Perlu dibuatkan jadwal pemeliharaan rutin (preventive maintenance) untuk VFD dan peralatan pendukung.

2. Diperlukan penambahan harmonic filter untuk mengurangi total harmonic distortion.

3. Untuk menambah kehandalan diperlukan spare VFD.

4. Redesain ini bisa diterapkan pada penggerak Submerged Scrapper Conveyor (SSC) di unit pembangkit PLTU batubara lainnya.

\section{DAFTAR PUSTAKA}

Corporation, Termokimik. 1993. Ash Handling Digital System Manual Book 1. Probolinggo: s.n., 1993.

Corporation, Termokimik. 1993. Ash Handling Manual Maintenance Part 1. Probolinggo: s.n., 1993.

Corporation, Termokimik. 1993. Ash Handling Manual Operation Part 1. Probolinggo: s.n., 1993.

Siemens. 2013. Sinamics G120 Inverter Operating Instruction. Germany : s.n., 2013.

ABB Drive. 2014. ACS550 - $01-087 A-4$ User Manual. English : s.n., 2014.

Industrial System, General Electric. 2007. Drive Basic System. USA : s.n., 2007.

Ishak Effendi, Penerapan Variable Frequency Drive Pada Motor Fuel Screw Feeder Untuk Bahan Bakar Pada 
JEECOM, Vol. 1, No. 1, Oktober 2019

Sistem Boiler, Januari 2014, Volume 2, No. 1.

Deni Nurul Huda, Pengujian Unjuk Kerja Variable Speed Drive VF-S9 Dengan Beban 3 Fasa 1 Horse Power, artikel ilmiah, 2012.

Emmanuel Agung Nugroho, Implementasi Sistem Kendali Variable Speed Drive Pada Inverter 3 Fasa Menggunakan Mikrokontroller AT89S52, April 2018, Volume 9, No. 1.

Schneider. 2013. Modicon Quantum User Manual. English : s.n., 20013 